\title{
Electropermeabilization of endocytotic vesicles in B16 F1 mouse melanoma cells
}

\author{
Tina Batista Napotnik • Matej Reberšek • \\ Tadej Kotnik • Eric Lebrasseur • \\ Gonzalo Cabodevila $\cdot$ Damijan Miklavčič
}

Received: 15 October 2009/Accepted: 18 March 2010/Published online: 2 April 2010

(C) The Author(s) 2010. This article is published with open access at Springerlink.com

\begin{abstract}
It has been reported previously that electric pulses of sufficiently high voltage and short duration can permeabilize the membranes of various organelles inside living cells. In this article, we describe electropermeabilization of endocytotic vesicles in B16 F1 mouse melanoma cells. The cells were exposed to short, high-voltage electric pulses (from 1 to 20 pulses, $60 \mathrm{~ns}, 50 \mathrm{kV} / \mathrm{cm}$, repetition frequency $1 \mathrm{kHz}$ ). We observed that 10 and 20 such pulses induced permeabilization of membranes of endocytotic vesicles, detected by release of lucifer yellow from the vesicles into the cytosol. Simultaneously, we detected uptake of propidium iodide through plasma membrane in the same cells. With higher number of pulses permeabilization of the membranes of endocytotic vesicles by pulses of given parameters is accompanied by permeabilization of plasma membrane. However, with lower number of pulses only permeabilization of the plasma membrane was detected.
\end{abstract}

Keywords Nanosecond electrical pulses .

Endocytotic vesicles $\cdot$ Lucifer yellow $\cdot$ Plasma membrane . Electropermeabilization

\author{
Abbreviations \\ PI Propidium iodide \\ LY Lucifer yellow \\ EMEM Eagle's minimum essential medium
}

T. B. Napotnik · M. Reberšek · T. Kotnik · D. Miklavčič ( $₫)$ Faculty of Electrical Engineering, University of Ljubljana, Tržaška 25, 1000 Ljubljana, Slovenia

e-mail: Damijan.Miklavcic@fe.uni-lj.si

E. Lebrasseur - G. Cabodevila

ENSMM, CNRS, Institut FEMTO-ST, 32 Avenue de

l'observatoire, 2504 Besançon CEDEX, France

\section{Introduction}

When a cell is exposed to sufficiently high electric field, the cell membrane permeability is increased [34, 51, 61]. The phenomenon termed as electropermeabilization has been studied for several decades and has already found numerous applications for intracellular drug and gene delivery in oncology (electrochemotherapy), gene therapy, and cell biology, for transdermal drug delivery, insertion of proteins into cells, fusion of cells, sterilization, and tissue ablation [1, 12, 13, 33, 37, 41, 42, 49, 53].

Recently, technological advances led to the development of devices with an ability to generate electric pulses with substantially shorter durations and higher field strengths compared to those used for classical electroporation $[8,31,47]$. For brevity, such pulses, with durations of up to hundred nanoseconds and electric field strengths of a few tens of $\mathrm{kV} / \mathrm{cm}$, will henceforth be referred to as "nanosecond electric pulses," or "nsEP". It has been suggested that application of such pulses to biological cells can cause permeabilization of internal membranes without causing permeabilization of the plasma membrane [48].

Effects of nsEP on cells depend on the physical parameters of the pulses delivered (duration, voltage, number of pulses in a pulse train, and repetition rate) [26, $50,56]$. When longer pulse trains or higher voltage nsEP are applied, cells undergo necrotic cell death, as a result of damaged plasma membrane [19, 22, 38, 39]. When shorter pulse trains and/or lower voltage nsEP are applied, however, cells undergo apoptotic cell death [4-6, 22, 50]. Apoptosis was also shown in vivo and ex vivo in tumors after applying nsEP, leading to partial or complete regression of tumors $[5,19,35]$ and is investigated as a promising new therapy for treating cancer. When cells survive, they exhibit calcium bursts $[11,15,54,59]$, 
permeabilization of intracellular granules [47], and large endocytosed vacuoles [52], externalization of phosphatidylserine [56-58, 60], damage in cell nuclei and DNA [14, $15,50]$, and platelet activation [62]. According to some of the reports, classical electroporation obtained using longer pulses (micro to milliseconds) with lower electric field (a few hundred $\mathrm{V} / \mathrm{cm}$ ) is also more efficient in obtaining gene transfection when combined with nsEP $[4,7]$.

Although the nsEP have strong effects on cell interior, theoretical models and simulations $[21,32,55]$ point out that generally, the plasma membrane is also affected. Experimental reports show that plasma membrane is depolarized [18] as well as permeabilized [26, 38, 40] by nsEP. It was suggested that pores in the plasma membrane caused by nanosecond pulses are smaller ("nanopores") than those caused by conventional electroporation [18, 20, 25, 56, 57].

The permeabilization of organelle membranes by applying nsEP has not yet been fully explored. In our study, we simultaneously used two fluorescent dyes, lucifer yellow (LY) and propidium iodide (PI), to monitor permeabilization of endocytotic vesicles and the plasma membrane, respectively, caused by the exposure of cells to trains of nsEP. We show that permeabilization of endocytotic vesicles can be achieved, but in our experiments, it was always accompanied by permeabilization of the plasma membrane.

\section{Materials and methods}

\subsection{Cells and labeling}

B16 F1 mouse melanoma cells (ATCC, Manassas, VA, USA) were plated in Eagle's minimum essential medium (EMEM) with L-glutamine supplemented with $10 \%$ FBS (Sigma-Aldrich, St. Louis, MA, USA) and antibiotics crystacylin and gentamycin, in 6-well plates, one or two days before experiments, with the concentration of $10^{4}$ or $5 \times 10^{3}$ cells $/ \mathrm{cm}^{2}$, respectively. The cells were first loaded with $1 \mathrm{mM}$ lucifer yellow (Sigma-Aldrich, St. Louis, MA, USA) [3, 44] in porating phosphate buffer, consisting of $250 \mathrm{nM}$ sucrose, $10 \mathrm{mM}$ phosphate $\left(\mathrm{K}_{2} \mathrm{HPO}_{4} / \mathrm{KH}_{2} \mathrm{PO}_{4}\right)$, and $1 \mathrm{mM} \mathrm{MgCl} 2, \mathrm{pH} 7.4$ [10,53], incubated for $2 \mathrm{~h}$ at $37^{\circ} \mathrm{C}$ in $\mathrm{CO}_{2}$ incubator. Cells were washed three times with EMEM culture medium, trypsinized, centrifuged in EMEM $\left(1000 \mathrm{rpm}, 5 \mathrm{~min}, 4^{\circ} \mathrm{C}\right)$, and suspended in poration phosphate buffer in concentration $10^{6}$ cells $/ \mathrm{ml}$. Propidium iodide (Sigma-Aldrich, St. Louis, MA, USA) weighing $100 \mu \mathrm{g} / \mathrm{ml}$ was added just before pulsing to $20 \mu \mathrm{l}$ of cell suspension [43] which was placed onto the electrodes that were positioned under a fluorescence microscope (Zeiss, Göttingen, Germany) and observed using $40 \times$ objective. Cells were allowed about 5 min to settle down to the electrodes. Phase contrast and fluorescent images were taken just before pulsing, immediately after pulsing, and 1, 2,5 , and $10 \mathrm{~min}$ after pulsing. For observing $\mathrm{LY}, \lambda_{\mathrm{ex}}$ was $425 \mathrm{~nm}$, and $\lambda_{\mathrm{em}}$ was $510 \mathrm{~nm}$; and for PI, $\lambda_{\mathrm{ex}}$ was $540 \mathrm{~nm}$, and $\lambda_{\mathrm{em}}$ was $640 \mathrm{~nm}$.

\subsection{Exposure of cells to nsEP}

The pulses were delivered by a modified Blumlein generator configured for generating pulses with durations in the nanosecond range and high-repetition frequencies, with adjustable duration and polarity, using synchronized switch control as described elsewhere [46]. The electrodes made of gold (see the fabrication below) were deposited onto a microscope cover glass and placed under a fluorescence microscope. The gap between the two electrodes was $100 \mu \mathrm{m}$. Cells were pulsed with $1-5,10$, and 20 electric pulses of $60 \mathrm{~ns}$ duration and $50 \mathrm{kV} / \mathrm{cm}$ field strength, $1 \mathrm{kHz}$ repetition frequency, $30 \mathrm{~ns}$ rise time, and $30 \mathrm{~ns}$ fall time (see Fig. 1). Control cells were handled the same way as pulsed cells, only without pulsing.

\subsection{Electrodes fabrication}

The glass substrate $(1 \times 2$ in., $130-\mu \mathrm{m}$ thickness $)$ was cleaned by acetone, ethanol, and deionized water, followed by piranha etching (a 1:1 mixture of sulphuric acid $\left(\mathrm{H}_{2} \mathrm{SO}_{4}\right)$ and hydrogen peroxide $\left.\left(\mathrm{H}_{2} \mathrm{O}_{2}\right)\right)$. A 50-nm layer of chromium was sputtered on the glass in a DC sputter (Plassys, Marolles-en Hurepoix, France). Subsequently, the gold layer was deposited by alternating $30 \mathrm{~s}$ of sputtering with a pause of $30 \mathrm{~s}$. After $20 \mathrm{~min}$ of deposition, we obtained a 2.1- $\mu \mathrm{m}$-thick layer of gold.

A 1.8- $\mu$ m-thick positive photoresist (Microposit S1818; Rohm and Haas Electronic Materials LLC, Philadelphia, PA, USA) was spin-coated on the substrate at $4000 \mathrm{rpm}$ and soft-baked at $90^{\circ} \mathrm{C}$ for $2 \mathrm{~min}$ on a hotplate. The photoresist was then exposed for $5 \mathrm{~s}$ with a power of $20 \mathrm{~mW} / \mathrm{cm}^{2}$ on a mask aligner using soft contact, developed using Megaposit MF-26A developer (Rohm and Haas Electronic Materials LLC, Philadelphia, PA, USA) for $10 \mathrm{~min}$ and rinsed in deionized water during $10 \mathrm{~min}$. The photoresist mask was then hardbaked at $120^{\circ} \mathrm{C}$ on a hotplate for $10 \mathrm{~min}$.

The gold layer was then etched using Gold etch TFA (Transene, Danvers, MA, USA) for about $10 \mathrm{~min}$. Finally, the thin layer of chromium is etched in "chrome etch 18 " (OSC, Bitterfeld, Germany) for $1 \mathrm{~min}$ and rinsed in deionized water for $10 \mathrm{~min}$.

\subsection{Image and statistical analysis}

Fluorescence images were analyzed with open source image processing software ImageJ (NIH, Bethesda, MD, 
Fig. 1 A typical nanosecond pulse used in our study (maximal voltage $500 \mathrm{~V}$, full width at half maximum $60 \mathrm{~ns}$, rise time $30 \mathrm{~ns}$, and fall time $30 \mathrm{~ns})$. Nanosecond pulse was measured on the electrode level by oscilloscope (WavePro 7300A, LeCroy, USA) using a high-voltage probe (PPE2 $\mathrm{kV}$, LeCroy, USA). Timebase was set to $20 \mathrm{~ns} / \mathrm{div}$ and voltage sensitivity to $200 \mathrm{~V} / \mathrm{div}$

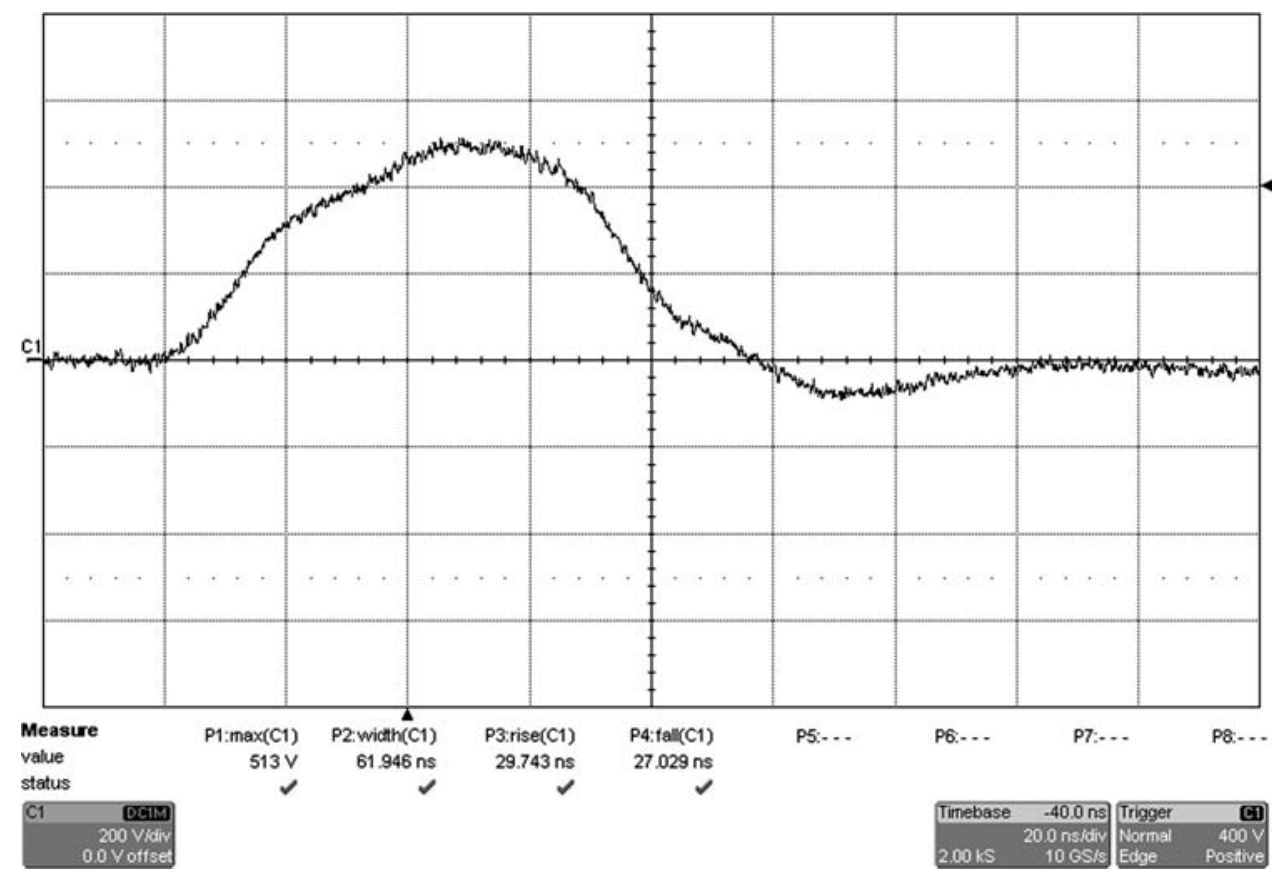

USA; http://rsbweb.nih.gov/ij/). In each image, $8-15$ cells that contained endocytotic vesicles were analyzed. Each series of experiments were repeated 5 times. Statistical analysis was performed using software Excel (Microsoft Corp.) and Sigmastat (Systat Software Inc.).

For LY, the mean value and the standard deviation of the intensity of pixels were determined in the areas of the image corresponding to the cells, first before pulsing and then $10 \mathrm{~min}$ after pulsing. The release of LY from permeabilized endocytotic vesicles into the cytosol caused a more evenly distributed fluorescence throughout the cell, which resulted in a significant decrease of the standard deviation of pixel intensities. A total LY intensity of cells was calculated as mean LY intensity multiplied by a number of pixels, corresponding to cells.

For PI, the mean value of the intensity of pixels was determined in the areas of the image corresponding to the cells, first before pulsing and then $10 \mathrm{~min}$ after pulsing. A total PI intensity of cells was calculated as mean PI intensity multiplied by a number of pixels, corresponding to cells.

The images of control cells were taken under the same conditions as pulsed cells, only without pulsing.

\section{Results}

Before pulsing, endocytotic vesicles in B16 F1 mouse melanoma cells loaded with LY were clearly visible in the images as concentrated small areas of high fluorescence ("bright dots") within the cytoplasm, with the cytosol devoid of the dye (Fig. 2b) [3]. Most of the cells also excluded PI (Fig. 2c), reflecting an intact plasma membrane. Control cells (that were not pulsed) retained LY in their vesicles and excluded PI even 10 min after they were put onto the electrodes and settled down (results not shown).

When we applied a train of 20 pulses of 60 ns duration, $50 \mathrm{kV} / \mathrm{cm}, 1-\mathrm{kHz}$ repetition frequency, however, most of the endocytotic vesicles were permeabilized, resulting in LY release from the vesicles into the cytosol. After a duration of 10 min post pulsing, the "bright dots" were not visible anymore, and the cell interior became stained with LY much more uniformly (Fig. 2h). With a lower number of pulses applied (10 pulses), the leakage of LY from the vesicles was smaller (the "bright dots" faded but stil not as much as in the case of 20 pulses).

When cells were pulsed with 5 such pulses or less, the release of LY from the vesicles was not detected, and "bright dots" were still present $10 \mathrm{~min}$ after pulsing (Fig. 2e).

We performed statistical analysis of LY fluorescence intensity. As we can see in Fig. 3, only with a train of 10 or 20 pulses, a decrease of SD value of LY reflected the release of LY from the endocytotic vesicles. Compared to the control cells, where the SD value after 10 min was $1.1 \pm 0.0$ of SD before pulsing, this value decreased significantly to $0.8 \pm 0.1$ and $0.7 \pm 0.2$ of SD before pulsing for trains of 10 and 20 pulses, respectively.

The cells also shrunk $(12.3 \pm 2.7 \%$ reduction in cell diameter after applying 20 pulses). Because the cells shrunk, we calculated also total LY intensity (mean LY intensity 
Fig. 2 LY release and PI uptake after applying nsEP. Phase contrast, LY and PI images of cells before pulsing, and $10 \mathrm{~min}$ after applying 5 and 20 pulses (60 ns, $50 \mathrm{kV} / \mathrm{cm}$, and $1 \mathrm{kHz})$
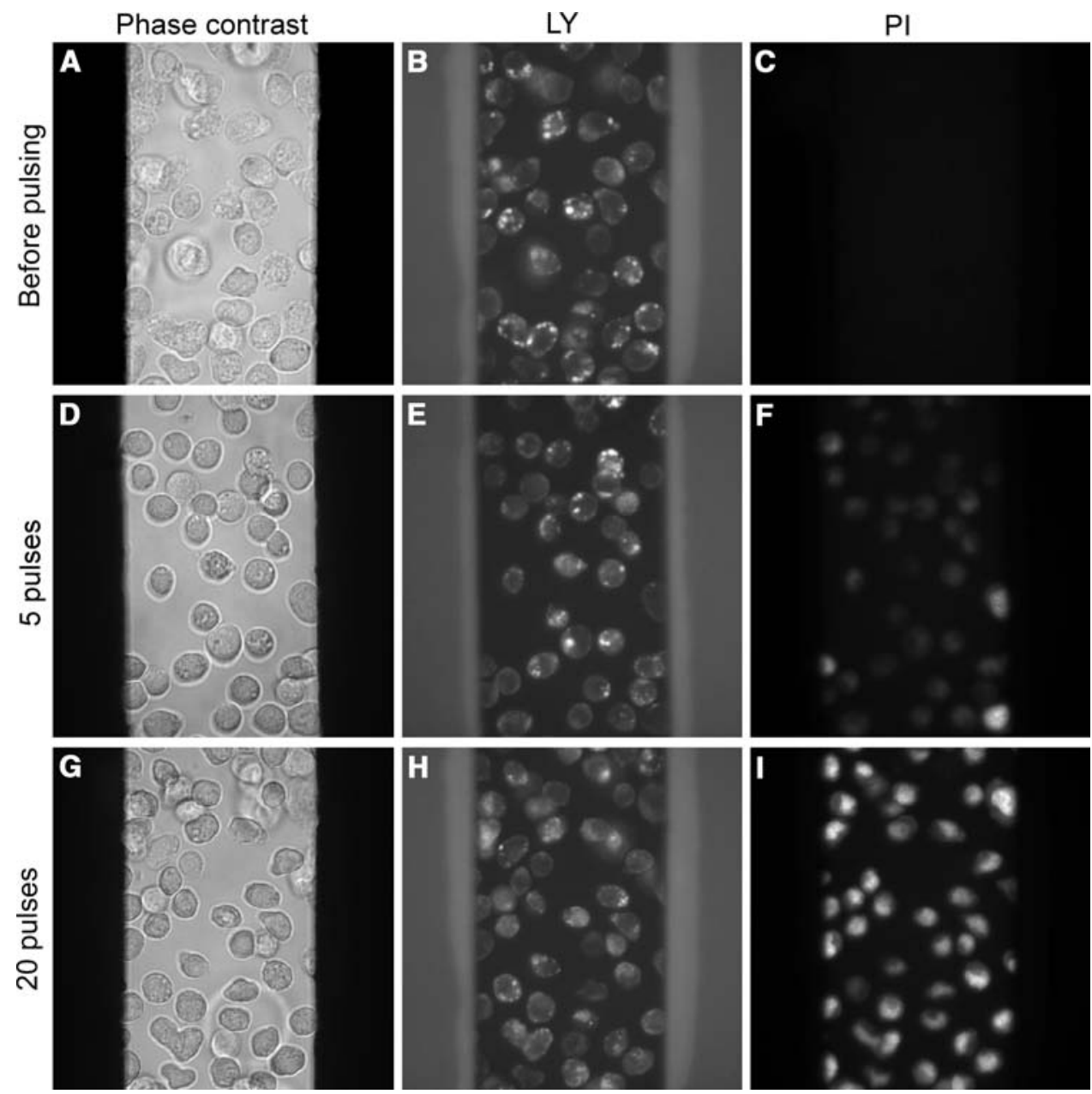

multiplied by the number of pixels corresponding to cells). Total LY intensity in cells decreased significantly $10 \mathrm{~min}$ after pulsing (with 20 pulses, total LY intensity in cells decreased for $19.6 \%$ of total LY intensity before pulsing).

However, when the PI uptake was monitored simultaneously in cells loaded with LY, we observed that $10 \mathrm{~min}$ after pulsing, PI entered the cells even at shorter pulse trains (Fig. 2f): some PI have already entered through the plasma membrane after applying 5 pulses $(60 \mathrm{~ns}, 50 \mathrm{kV} / \mathrm{cm}$, $1 \mathrm{kHz}$ ) (Fig. 3). After 10 and 20 pulses (same pulse parameter values), the total PI intensity in cells was $2.5 \pm 0.8$ and $3.8 \pm 0.6$ times greater than before pulsing, respectively.

Time-scale analysis of LY release and PI uptake showed that both processes took place mainly during the first few minutes after pulsing (Fig. 4a and b).

\section{Discussion}

In this present study, we confirm that with the use of nsEP of the following parameters, namely, 10 or 20 pulses of $50 \mathrm{kV} / \mathrm{cm}$ field strength, $60 \mathrm{~ns}$ duration, and $1 \mathrm{kHz}$ pulse repetition rate, endocytotic vesicles are permeabilized. Moreover, with simultaneous use of lucifer yellow (LY) and propidium iodide (PI), we were able to observe permeabilization of both endocytotic vesicle membranes and of plasma membrane in cells simultaneously.

The nsEP have a strong effect on cell interior. In this study, the vesicles released LY into the cytoplasm, and the cells became more evenly stained. With lower number of pulses, less LY is released from vesicles. When five or fewer pulses with the same parameters were applied, we did not observe any LY release from the vesicles (except of the vesicles in cells that were in direct contact with the electrodes). In previous reports, the organelles, such as granules in human eosinophils [47] and large endocytotic vesicles [52], were permeabilized without detectable plasma membrane damage (using calcein and ethidium homodimer for detecting plasma membrane permeabilization, respectively). In our study, with the specific nsEP parameters given above, we achieved the permeabilization of the plasma membrane simultaneously with the permeabilization of endocytotic vesicles, and PI always entered the cells in which LY was released from the endocytotic vesicles. 


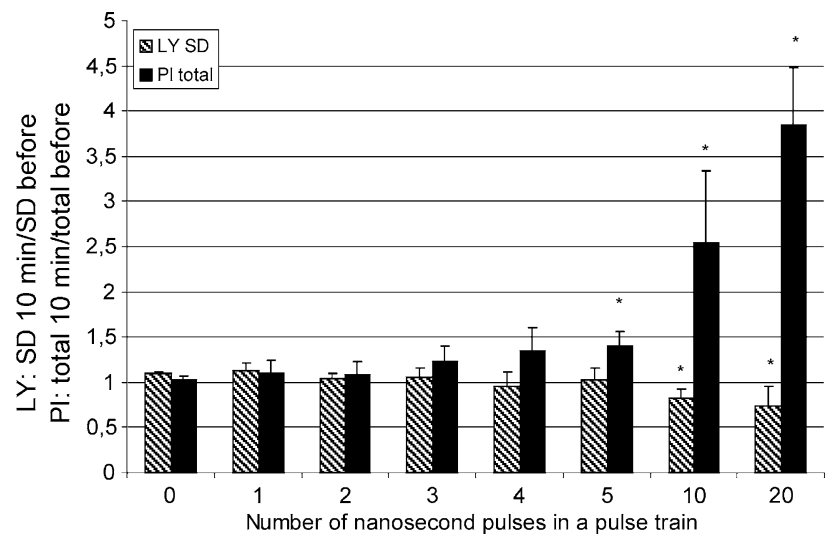

Fig. 3 LY release and PI uptake after applying trains of nsEP with various numbers of pulses. For LY: SD of fluorescence intensities of pixels corresponding to cells $10 \mathrm{~min}$ after pulsing divided by SD of fluorescence intensities of pixels corresponding to cells before pulsing. For PI: total PI intensity of cells 10 min after pulsing, divided by total PI intensity before pulsing. SD of LY decreases significantly after applying 10 and 20 pulses, implying that LY is released from endocytotic vesicles. PI enters the cells already after the application of 5 pulses, implying that the plasma membrane is permeabilized. The pulses: $60 \mathrm{~ns}, 50 \mathrm{kV} / \mathrm{cm}, 1 \mathrm{kHz}$ repetition frequency. Each value represent mean of 5 independent experiments \pm SD. * Indicate significant differences from control-zero pulses $(P<0.05)$

It has been suggested that when the pulses are shorter than the charging time of the plasma membrane, the effects of pulses on the plasma membrane are negligible and only internal membranes are affected [48]. In our earlier theoretical study [32], we have shown that sufficiently short (at most hundreds of ns) and strong (at least $\mathrm{MV} / \mathrm{m}$ ) electric pulses could cause selective poration of organelle membranes, with the plasma membrane remaining intact. However, this would only be possible under very specific conditions (the organelle membranes with a considerably lower dielectric permittivity than the plasma membrane, and/or the cytosol with a much lower electric conductivity than the organelle interior). As it is highly questionable whether such conditions are physiologically realistic for any type of organelle, this suggests that permeabilization of organelles is typically, and perhaps even in all cases, accompanied by a certain extent of plasma membrane permeabilization.

The results of this experimental study show that endocytotic vesicles can be permeabilized, but suggest that their permeabilization is not selective, i.e., it is always accompanied by permeabilization of the plasma membrane. The permeabilization of both endocytotic vesicles and plasma membrane was also expected according to the theoretical predictions outlined in our previous theoretical study [32] and summarized briefly in the preceding paragraph.

LY is a classical marker of a fluid-phase endocytosis $[28,45]$ which consists of clathrin-dependent and clathrinindependent pathways, such as macropinosomes [16, 27].
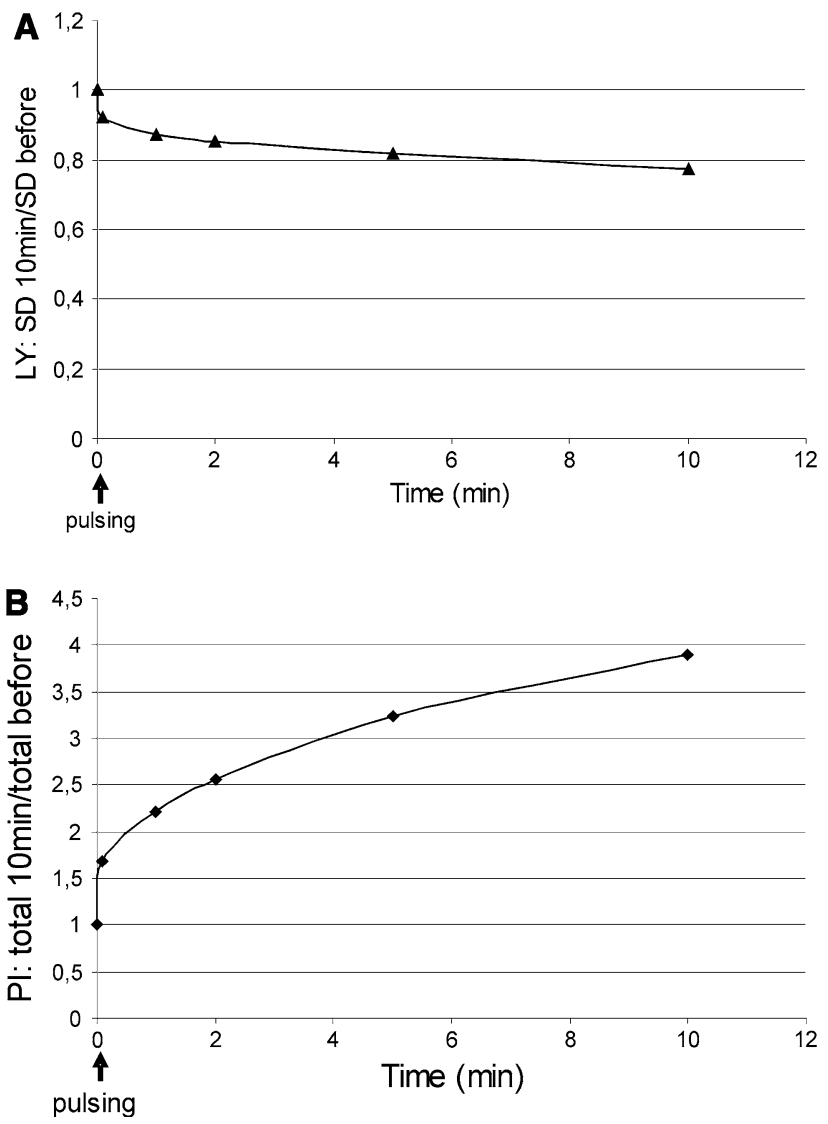

Fig. 4 Time-scale of a release of LY from endocytotic vesicles and of PI uptake after applying 20 pulses, $60 \mathrm{~ns}, 50 \mathrm{kV} / \mathrm{cm}$, and $1 \mathrm{kHz}$ repetition rate. Cells were pulsed immediately after images of unpulsed cells (at time zero) were taken. a Time-scale of a release of LY from endocytotic vesicles. b Time-scale of PI uptake. Each value represent mean of 5 independent experiments

The clathrin coat is a mesh-like scaffolding, and not a continuous closed surface covering the membrane; furthermore this coat disassembles rather rapidly after the vesicle formation [17, 24]. Since endocytotic vesicles are formed as invaginations of specific parts of plasma membrane (rafts), their membranes might have specific composition differing from the rest of the plasma membranes $[23,30]$. The ionic compositions of the vesicle interior and the cytosol do differ to an extent, and the ongoing chemical processes in the vesicles could also contribute to a difference in electric conductivities. However, it is highly unlikely that these differences in cell/vesicle membranes and interiors could be sufficiently large (10 times or more) to allow selective poration of the endocytotic vesicles.

An additional theoretical argument in favor of the finding that vesicle membrane permeabilization only occurs with (or after) the plasma membrane permeabilization is the fact that, generally, the internal vesicles are electrically shielded from the external electric field by the plasma membrane. During the first few nanoseconds after the onset of the external field, this field penetrates the entire cell, but 
subsequently the polarization of the plasma membrane starts neutralizing this transient effect, with the plasma membrane becoming increasingly more polarized than the membranes of internal organelles and vesicles. Therefore, as long as all the membranes are intact, the plasma membrane is more likely to become permeabilized than the internal organelles and vesicles. However, once the plasma membrane is permeabilized, this partly inhibits the shielding process (both during the ongoing pulse and during subsequent pulses that may follow). As a result, the peak voltage induced by the external field on the vesicle membranes is somewhat higher than without permeabilization of the plasma membrane, and the permeabilization of these membranes becomes more likely, particularly when further pulses are applied after the plasma membrane is already permeabilized. We need to stress, however, that the peak voltage induced in the cytoplasm when the plasma membrane is intact is strongly dependent on the rise time of the external pulse. Furthermore, the voltage when the plasma membrane is "porated" depends on the resulting conductance of the membrane during the pulse. Exact dynamics and the extent of these effects, however, are still not fully known and deserve more investigations.

The analyses of changes in total fluorescence of LY and PI in cells reveal that after applying 20 pulses, total fluorescence of LY is decreased to $19.6 \%$, whereas total PI fluorescence is increased for $285 \%$ of values before pulsing. When PI binds to nucleic acids, its fluorescence is enhanced by approximately 20-30 fold [2], and so the amount of PI in the cell is approximately $9.5-14.3 \%$ higher than before pulsing. Therefore, we conclude that the two molecules of comparable sizes cross the compromized plasma membrane in similar amounts.

A majority of PI enter the cells shortly after the electroporation. On the other hand, LY is also released from the vesicles mainly during the first few minutes after pulsing. For PI, the slower rise of PI fluorescence may be caused by a resealing of the membrane [29], a drop of a concentration gradient, or the saturation of binding sites $[9,36]$. In the case of LY, however, only the first two effects may play a role in slowing down a release of LY from endocytotic vesicles as $L Y$ remains unbound.

\section{Conclusions}

In this study, we experimentally confirmed that with the use of our nsEP (20 pulses of $50 \mathrm{kV} / \mathrm{cm}$ field strength, $60 \mathrm{~ns}$ duration, and $1 \mathrm{kHz}$ pulse repetition rate) endocytotic vesicles can be permeabilized. We also observed that the plasma membrane permeabilization occurred simultaneously with the permeabilization of internal membranes. With the application of five pulses or less, we were able to achieve the permeabilization of plasma membrane with no detectable release of LY from endocytotic vesicles. Although the nsEP may cause more profound effects on internal membranes of the cell, we must be aware that the pulses of such parameters do not leave the plasma membrane intact.

Acknowledgments The study was supported by the grants Z2-7046, Z2-2025, and P2-0249 from the Slovenian Research Agency (ARRS).

Open Access This article is distributed under the terms of the Creative Commons Attribution Noncommercial License which permits any noncommercial use, distribution, and reproduction in any medium, provided the original author(s) and source are credited.

\section{References}

1. Al-Sakere B, André F, Bernat C et al (2007) Tumor ablation with irreversible electroporation. PLoS One 2:e1135

2. Arndt-Jovin D, Jovin T (1989) Fluorescence labeling and microscopy of DNA. Methods Cell Biol 30:417-448

3. Awasthi A, Matsunaga Y, Yamada T (2005) Amyloid-beta causes apoptosis of neuronal cells via caspase cascade, which can be prevented by amyloid-beta-derived short peptides. Exp Neurol 196:282-289

4. Beebe SJ, Blackmore PF, White J et al (2004) Nanosecond pulsed electric fields modulate cell function through intracellular signal transduction mechanisms. Physiol Meas 25:1077-1093

5. Beebe SJ, Fox PM, Rec LJ et al (2002) Nanosecond pulsed electric field (nsPEF) effects on cells and tissues: apoptosis induction and tumor growth inhibition. IEEE Trans Plasma Sci 30:286-292

6. Beebe SJ, Fox PM, Rec LJ et al (2003) Nanosecond, highintensity pulsed electric fields induce apoptosis in human cells. Faseb J 17:1493-1495

7. Beebe SJ, White J, Blackmore PF et al (2003) Diverse effects of nanosecond pulsed electric fields on cells and tissues. DNA Cell Biol 22:785-796

8. Behrend M, Kuthi A, Gu XY et al (2003) Pulse generators for pulsed electric field exposure of biological cells and tissues. IEEE Trans Dielectr Electr Insul 10:820-825

9. Bertuzzi A, D’Agnano I, Gandolfi A et al (1990) Study of propidium iodide binding to DNA in intact cells by flow cytometry. Cell Biophys 17:257-267

10. Blangero C, Teissie J (1985) Ionic modulation of electrically induced fusion of mammalian cells. J Membr Biol 86:247-253

11. Buescher ES, Smith RR, Schoenbach K (2004) Submicrosecond intense pulsed electric field effects on intracellular free calcium: mechanisms and effects. IEEE Trans Plasma Sci 32:1563-1572

12. Cemazar M, Golzio M, Sersa G et al (2006) Electrically-assisted nucleic acids delivery to tissues in vivo: where do we stand? Curr Pharm Des 12:3817-3825

13. Chen C, Smye S, Robinson M et al (2006) Membrane electroporation theories: a review. Med Biol Eng Comput 44:5-14

14. Chen N, Garner A, Chen G et al (2007) Nanosecond electric pulses penetrate the nucleus and enhance speckle formation. Biochem Biophys Res Commun 364:220-225

15. Chen NY, Schoenbach KH, Kolb JF et al (2004) Leukemic cell intracellular responses to nanosecond electric fields. Biochem Biophys Res Commun 317:421-427

16. Conner S, Schmid S (2003) Regulated portals of entry into the cell. Nature 422:37-44

17. Edeling M, Smith C, Owen D (2006) Life of a clathrin coat: insights from clathrin and AP structures. Nat Rev Mol Cell Biol 7:32-44 
18. Frey W, White JA, Price RO et al (2006) Plasma membrane voltage changes during nanosecond pulsed electric field exposure. Biophys J 90:3608-3615

19. Garon EB, Sawcer D, Vernier PT et al (2007) In vitro and in vivo evaluation and a case report of intense nanosecond pulsed electric field as a local therapy for human malignancies. Int $\mathrm{J}$ Cancer 121:675-682

20. Gowrishankar TR, Esser AT, Vasilkoski Z et al (2006) Microdosimetry for conventional and supra-electroporation in cells with organelles. Biochem Biophys Res Commun 341:1266-1276

21. Gowrishankar TR, Weaver JC (2006) Electrical behavior and pore accumulation in a multicellular model for conventional and supra-electroporation. Biochem Biophys Res Commun 349: 643-653

22. Hall EH, Schoenbach KH, Beebe SJ (2007) Nanosecond pulsed electric fields induce apoptosis in p53-wildtype and p53-null HCT116 colon carcinoma cells. Apoptosis 12:1721-1731

23. Hanzal-Bayer M, Hancock J (2007) Lipid rafts and membrane traffic. FEBS Lett 581:2098-2104

24. Higgins M, McMahon H (2002) Snap-shots of clathrin-mediated endocytosis. Trends Biochem Sci 27:257-263

25. Hu Q, Joshi RP, Schoenbach KH (2005) Simulations of nanopore formation and phosphatidylserine externalization in lipid membranes subjected to a high-intensity, ultrashort electric pulse. Phys Rev E 72:10

26. Ibey B, Xiao S, Schoenbach K et al (2009) Plasma membrane permeabilization by 60 - and 600 -ns electric pulses is determined by the absorbed dose. Bioelectromagnetics 30:92-99

27. Johannes L, Lamaze C (2002) Clathrin-dependent or not: is it still the question? Traffic 3:443-451

28. Jones N, Willingham M (1999) Modified LDLs are internalized by macrophages in part via macropinocytosis. Anat Rec 255: $57-68$

29. Kanduser M, Sentjurc M, Miklavcic D (2006) Cell membrane fluidity related to electroporation and resealing. Eur Biophys $\mathbf{J}$ 35:196-204

30. Kirkham M, Parton R (2005) Clathrin-independent endocytosis: new insights into caveolae and non-caveolar lipid raft carriers. Biochim Biophys Acta 1745:273-286

31. Kolb JF, Kono S, Schoenbach KH (2006) Nanosecond pulsed electric field generators for the study of subcellular effects. Bioelectromagnetics 27:172-187

32. Kotnik T, Miklavcic D (2006) Theoretical evaluation of voltage inducement on internal membranes of biological cells exposed to electric fields. Biophys J 90:480-491

33. Mali B, Jarm T, Corovic S et al (2008) The effect of electroporation pulses on functioning of the heart. Med Biol Eng Comput 46:745-757

34. Neumann E, Sowers A, Jordan C (1989) Electroporation and electrofusion in cell biology. Plenum Press, New York

35. Nuccitelli R, Pliquett U, Chen XH et al (2006) Nanosecond pulsed electric fields cause melanomas to self-destruct. Biochem Biophys Res Commun 343:351-360

36. O'Brien I, Murray B, Baguley B et al (1998) Major changes in chromatin condensation suggest the presence of an apoptotic pathway in plant cells. Exp Cell Res 241:46-54

37. Oshima T, Sato M (2004) Bacterial sterilization and intracellular protein release by a pulsed electric field. Adv Biochem Eng Biotechnol 90:113-133

38. Pakhomov A, Kolb J, White J et al (2007) Long-lasting plasma membrane permeabilization in mammalian cells by nanosecond pulsed electric field (nsPEF). Bioelectromagnetics 28:655-663

39. Pakhomov AG, Phinney A, Ashmore J et al (2004) Characterization of the cytotoxic effect of high-intensity, 10-ns duration electrical pulses. IEEE Trans Plasma Sci 32:1579-1586
40. Pakhomov AG, Shevin R, White JA et al (2007) Membrane permeabilization and cell damage by ultrashort electric field shocks. Arch Biochem Biophys 465:109-118

41. Pliquett U (2003) Joule heating during solid tissue electroporation. Med Biol Eng Comput 41:215-219

42. Prausnitz M, Langer R (2008) Transdermal drug delivery. Nat Biotechnol 26:1261-1268

43. Pucihar G, Kotnik T, Teissie J et al (2007) Electropermeabilization of dense cell suspensions. Eur Biophys J Biophys Lett 36:173-185

44. Pucihar G, Mir LM, Miklavcic D (2002) The effect of pulse repetition frequency on the uptake into electropermeabilized cells in vitro with possible applications in electrochemotherapy. Bioelectrochemistry 57:167-172

45. Racoosin E, Swanson J (1992) M-CSF-induced macropinocytosis increases solute endocytosis but not receptor-mediated endocytosis in mouse macrophages. J Cell Sci 102(Pt 4):867-880

46. Rebersek M, Kranjc M, Pavliha D et al (2009) Blumlein configuration for high repetition rate pulse generation of variable duration and polarity using synchronized switch control. IEEE Trans Biomed Eng 56:2642-2648

47. Schoenbach KH, Beebe SJ, Buescher ES (2001) Intracellular effect of ultrashort electrical pulses. Bioelectromagnetics 22:440-448

48. Schoenbach KH, Joshi RP, Kolb JF et al (2004) Ultrashort electrical pulses open a new gateway into biological cells. Proceedings of the IEEE 92:1122-1137

49. Sersa G, Miklavcic D, Cemazar M et al (2008) Electrochemotherapy in treatment of tumours. Eur J Surg Oncol 34:232-240

50. Stacey M, Stickley J, Fox P et al (2003) Differential effects in cells exposed to ultra-short, high intensity electric fields: cell survival, DNA damage, and cell cycle analysis. Mutat Res Genetic Toxicol Environ Mutagen 542:65-75

51. Staempfli R (1958) Reversible breakdown of the excitable membrane of a Ranvier node. Anais da Academia Brasileira de Ciencias 30:57

52. Tekle E, Oubrahim H, Dzekunov SM et al (2005) Selective field effects on intracellular vacuoles and vesicle membranes with nanosecond electric pulses. Biophys J 89:274-284

53. Trontelj K, Rebersek M, Kanduser M et al (2008) Optimization of bulk cell electrofusion in vitro for production of human-mouse heterohybridoma cells. Bioelectrochemistry 74:124-129

54. Vernier P, Sun Y, Chen M et al (2008) Nanosecond electric pulse-induced calcium entry into chromaffin cells. Bioelectrochemistry $73: 1-4$

55. Vernier P, Ziegler M (2007) Nanosecond field alignment of head group and water dipoles in electroporating phospholipid bilayers. J Phys Chem B 111:12993-12996

56. Vernier PT, Sun YH, Gundersen MA (2006) Nanoelectropulsedriven membrane perturbation and small molecule permeabilization. BMC Cell Biol 7:16

57. Vernier PT, Sun YH, Marcu L et al (2004) Nanoelectropulseinduced phosphatidylserine translocation. Biophys J 86:4040-4048

58. Vernier PT, Sun YH, Marcu L et al (2004) Nanosecond pulsed electric fields perturb membrane phospholipids in $\mathrm{T}$ lymphoblasts. Febs Lett 572:103-108

59. Vernier PT, Sun YH, Marcu L et al (2003) Calcium bursts induced by nanosecond electric pulses. Biochem Biophys Res Commun 310:286-295

60. Vernier PT, Ziegler MJ, Sun YH et al (2006) Nanopore-facilitated, voltage-driven phosphatidylserine translocation in lipid bilayers-in cells and in silico. Phys Biol 3:233-247

61. Weaver JC, Chizmadzhev YA (1996) Theory of electroporation: a review. Bioelectrochem Bioenerg 41:135-160

62. Zhang J, Blackmore P, Hargrave B et al (2008) Nanosecond pulse electric field (nanopulse): a novel non-ligand agonist for platelet activation. Arch Biochem Biophys 471:240-248 